\title{
The effect of rate of reinforcement and time in session on preference for variability
}

\author{
FRANCES K. MCSWEENEY, BENJAMIN P. KOWAL, and ERIC S. MURPHY \\ Washington State University, Pullman, Washington
}

\begin{abstract}
Pigeons pecked keys on concurrent-chains schedules that provided a variable interval 30-sec schedule in the initial link. One terminal link provided reinforcers in a fixed manner; the other provided reinforcers in a variable manner with the same arithmetic mean as the fixed alternative. In Experiment 1, the terminal links provided fixed and variable interval schedules. In Experiment 2, the terminal links provided reinforcers after a fixed or a variable delay following the response that produced them. In Experiment 3 , the terminal links provided reinforcers that were fixed or variable in size. Rate of reinforcement was varied by changing the scheduled interreinforcer interval in the terminal link from 5 to $225 \mathrm{sec}$. The subjects usually preferred the variable option in Experiments 1 and 2 but differed in preference in Experiment 3. The preference for variability was usually stronger for lower (longer terminal links) than for higher (shorter terminal links) rates of reinforcement. Preference did not change systematically with time in the session. Some aspects of these results are inconsistent with explanations for the preference for variability in terms of scaling factors, scalar expectancy theory, risk-sensitive models of optimal foraging theory, and habituation to the reinforcer. Initial-link response rates also changed within sessions when the schedules provided high, but not low, rates of reinforcement. Withinsession changes in responding were similar for the two initial links. These similarities imply that habituation to the reinforcer is represented differently in theories of choice than are other variables related to reinforcement.
\end{abstract}

Animals often prefer variable to fixed outcomes, although they may be indifferent to, or even prefer, fixedrather than variable-sized reinforcers (Table 1; see Kacelnik \& Bateson, 1996, for a review). Some authors have used a scaling approach to explain this preference. That is, they have argued that animals prefer the schedule with the highest value. Subjects prefer variable to fixed rewards with the same arithmetic mean because the animals calculate the value of a variable schedule, using the geometric (e.g., Fantino, 1967) or harmonic (e.g., Grace, 1996; Killeen, 1968) mean. These means are smaller than the arithmetic mean. Hence, animals prefer a variable to a fixed alternative with the same arithmetic mean when smaller numbers indicate the better alternative (e.g., interreinforcer intervals or delays to reinforcement). Animals prefer the fixed to the variable alternative when smaller numbers indicate the worse alternative (e.g., reinforcer size). Contrary to scaling theory, some have argued that no single principle can be used to transform aperiodic schedules into their periodic equivalents. Instead, the appropriate transformation

Preparation of this manuscript was partially supported by Grant R01 MH61720 from the National Institute of Mental Health to F.K.M. Some of these data were presented at the 2001 meeting of the Northwest Association for Behavior Analysis in Victoria, British Columbia, and at the 2002 meeting of the Association for Behavior Analysis in Toronto, Ontario. Experiment 3 was conducted as part of a master's thesis submitted to the Department of Psychology, Washington State University, by B.P.K. Correspondence concerning this article should be addressed to F. K. McSweeney, Department of Psychology, Washington State University, Pullman, WA 99164-4820(e-mail: fkmcs@ mail.wsu.edu). varies with the size of the smallest interreinforcer interval (e.g., Davison, 1969, 1972; Duncan \& Fantino, 1970; Navarick \& Fantino, 1972, 1974, 1975; Rider, 1983b; but see also Davison, 1972; Hursh \& Fantino, 1973; Mazur, 1984, 1986).

Scalar expectancy theory (SET) explains the preference for variability in terms of differences in the shapes of the sampling distributions for the fixed and the variable alternatives. According to this theory, animals time events by using an accumulator that collects pulses from an internal pacemaker while the event is presented. The number of pulses is then compared with a number taken from a distribution of pulses in reference memory. Modifications of SET predict that variably arranged outcomes result in positively skewed distributions and that fixed outcomes result in normal distributions (e.g., Reboreda \& Kacelnik, 1991). Numbers taken from the normal, fixed outcome distribution are larger, on average, than numbers taken from the positively skewed, variable outcome distribution. Therefore, subjects prefer variable to fixed outcomes when smaller numbers represent the more favorable alternative (e.g., interreinforcer intervals). Subjects prefer fixed to variable outcomes when larger numbers represent better alternatives (e.g., amounts). Inconsistent with SET, animals sometimes prefer variable to fixed reinforcer sizes (Table 1).

Risk-sensitive models of optimal foraging theory (RST; e.g., Caraco, 1980; Houston \& McNamara, 1982; McNamara, 1996; Stephens \& Charnov, 1982) differ in detail, but several predict an energy budget rule (e.g., Caraco, Martindale, \& Whittam, 1980). According to this rule, foragers prefer a constant resource under a positive energy 
Table 1

Studies That Have Reported a Preference for Variable Over Fixed Reinforcers

\begin{abstract}
Mixed Interval (MI) or Variable Interval (VI) Schedules Are Preferred to Equally Rich Fixed Interval (FI) Schedules

Autor, 1969; Bateson \& Kacelnik, 1995; Case, Nichols, \& Fantino, 1995; Davison, 1969, 1972; Frankel \& vom Saal, 1976; Herrnstein, 1964; Hursh \& Fantino, 1973; Killeen, 1968; Lobb \& Davison, 1975; Navarick \& Fantino, 1972, 1975; Trevett, Davison, \& Williams, 1972

Mixed (MR) or Variable (VR) Ratio Schedules Are Preferred to Equally Rich Fixed Ratio (FR) Schedules

Ahearn, Hineline, \& David, 1992; Fantino, 1967; Mazur, 1986; Morris, 1986; Navarick \& Fantino, 1972; Rider, 1979, 1983a (note that Rider, 1983a, includes information on both sides of this issue); Sherman \& Thomas, 1968
\end{abstract}

More Variable VR Schedules Are Preferred to Less Variable VR Schedules Ha, 1991; Ha, Lehner, \& Farley, 1990

VI Schedules Are Preferred to Equally Rich FR Schedules Bacotti, 1977

VR Schedules Are Preferred to Equally Rich FI Schedules Rider, 1981

Variable Times From the Start of a Trial Are Preferred to Fixed Times
Logan, 1965; Reboreda \& Kacelnik, 1991

Variable or Mixed Delays From a Response to a Reinforcer Are Preferred to Fixed Delays Bateson \& Kacelnik, 1997; Cicerone, 1976; Mazur, 1984, 1986; Pubols, 1962; Rider, 1983b; Zabludoff, Wecker, \& Caraco, 1988 (note that Zabludoff et al. include information on both sides of this issue)

Preference for a Mixed Delay Increases as the Variability of the Delay Interval Increases Cicerone, 1976

Probabilistically Delivered Reinforcers are Preferred to Certain Reinforcers Mazur, 1988

Variable Amounts of Reinforcement May Be Preferred to Fixed Amounts

Essock \& Reese, 1974; Hastjarjo, Silberberg, \& Hursh, 1990; Hurly \& Oseen, 1999; Leventhal, Morrell, Morgan, \& Perkins, 1959; Mazur, 1988; Young, 1981

Exception: Animals May Be Indifferent or Prefer Fixed- to Variable-Sized Reinforcers Bateson \& Kacelnik, 1995; Battalio, Kagel, \& MacDonald, 1985; Essock \& Reese, 1974; Hamm \& Shettleworth, 1987; Hastjarjo et al., 1990; Ito, Takatsuru, \& Saeki, 2000; Kagel, MacDonald, Battalio, White, \& Green, 1986; Leventhal et al., 1959; Logan, 1965; Mazur, 1988; Menlove, Inden, \& Madden, 1979; Reboreda \& Kacelnik, 1991; Shafir, Wiegmann, Smith, \& Real, 1999; Staddon \& Innis, 1966

Note-A variable alternative is equally rich as a fixed alternative when the two have the same arithmetic means.

budget, but they prefer a variable resource under a negative energy budget. Positive energy budgets provide enough energy for the animal to meet its fitness needs. Negative energy budgets do not. Early versions of RST defined fitness solely in terms of survival. Therefore, these theories applied to small animals that were in danger of starving when foraging was interrupted (e.g., overnight; Lawes \& Perrin, 1995). More recent versions of RST broadened the definition of fitness to include such concerns as the ability to reproduce, migrate, or avoid predation (e.g., Bednekoff, 1996). As a result, larger animals, such as pigeons and rats, have been used to test RST (e.g., Ito, Takatsuru, $\&$ Saeki, 2000). Although many studies have looked for the predicted shift from risk aversion to risk proneness as resources become scarce, this shift has not always been observed (see Kacelnik \& Bateson, 1996, for a review).

A final potential explanation for the preference for variability has not been examined. McSweeney, Hinson, and Cannon (1996) argued that animals sensitize and then ha- bituate to the sensory properties of the reinforcer when the reinforcer is presented repeatedly over the course of an experimental session. The reinforcer loses its ability to support responding (its value) as habituation occurs. Habituation is slower when the stimulus is presented in a variable, rather than in a fixed, manner (e.g., Broster \& Rankin, 1994; Davis, 1970; Laming \& McKinney, 1990; but see also Graham, 1973). As a result, constant reinforcers should lose more of their value over a session than do variable reinforcers (Aoyama \& McSweeney, 2001). On average, subjects should prefer the more valuable variable reinforcers to the less valuable fixed reinforcers.

All of these theories predict a preference for variability under some conditions, but the details of their predictions differ substantially. Habituation theory predicts that preference for variability should be strongest when differences in habituation are strongest. Differences in habituation should be stronger later in the session than earlier, because these differences should accumulate with successive rein- 
forcer presentations. Differences in habituation should also be stronger at higher than at lower rates of reinforcement, because habituation is usually stronger for higher than for lower rates of stimulus presentation (e.g., Thompson \& Spencer, 1966). RST makes the opposite predictions. Animals should prefer the variable option more strongly when their energy budget is low. Therefore, if anything, they should prefer the variable option more strongly at the beginning of the session and when obtained rates of reinforcement are low. Finally, scaling theories and SET predict no change in the preference for variability as a function of time in the session or rate of reinforcement. Changes in deprivation should not alter the temporal discriminations that are the basis for preference in SET (e.g., Gibbon, 1977) or the scale used by the animal to determine the fixed equivalent of a variable outcome in scaling theories.

In the present experiments, concurrent-chains procedures were used to test these predictions (summarized in Table 2). In the concurrent-chains procedures, responding during each of two initial links produced occasional entry into a corresponding terminal link. One terminal link delivered a variable reinforcer; the other delivered a fixed reinforcer. Variability was created in three ways. In Experiment 1 , pigeons chose between equivalent fixed interval (FI) and variable interval (VI) schedules (relatively fixed vs. highly variable interreinforcer intervals). In Experiment 2, pigeons chose between equivalent fixed and variable delays between the reinforcer and the response that produced it. In Experiment 3, pigeons chose between equivalent fixed- and variable-sized reinforcers. In all cases, reinforcers or schedules were equivalent when the arithmetic mean of the variable alternative was the same as the fixed alternative. Preference for variability was measured by the proportion of initial-link responses emitted for the variable alternative. This measure was used because it has frequently been the measure of preference for terminal links. In the experiments, the effects of rate of reinforcement and time in session on the preference for variability were examined.

Concurrent-chains procedures were used because their results can be clearly interpreted. Stubbs and Pliskoff's (1969) procedure was used to randomly assign entrance into a particular terminal link with a probability of .5 after completion of the initial link. Because each terminal link ended after the delivery of one reinforcer, Stubbs and Pliskoff's procedure ensured that the subjects obtained equal numbers of reinforcers from the fixed and the variable al- ternatives. Therefore, choice of the variable outcome was clearly a preference for variability, rather than a preference for more reinforcers.

In all the experiments, obtained rate of reinforcement was varied by changing the schedule of reinforcement in the terminal link. Because each terminal link ended after the delivery of one reinforcer, varying the terminal-link schedule also altered terminal-link duration. Rate of reinforcement was altered by varying the terminal-link, rather than the initial-link, duration in order to bias the results against the predictions of habituation theory. Studies of concurrentchains responding often have reported an initial-link effect. That is, preferences are stronger in shorter than in longer initial links (e.g., Fantino, 1969; Fantino \& Davison, 1983). If this occurs and if rate of reinforcement is manipulated by varying initial-link duration, stronger preferences at higher rates of reinforcement might be due to the effect of changing initial-link duration, rather than to stronger habituation at higher rates of reinforcement. In contrast, preferences during concurrent-chains schedules are often stronger for longer than for shorter terminal links (e.g., MacEwen, 1972; Williams \& Fantino, 1978). Therefore, the present study would confirm the predictions of habituation theory only if the effect of habituation was strong enough to overcome the opposite effect of varying the duration of the terminal link.

To the best of our knowledge, studies have not been conducted in which the effect of rate of reinforcement or time in session on preferences for variability has been systematically examined. The effect of energy budget has been investigated (see Kacelnik \& Bateson, 1996, for a review), but it usually has been manipulated by varying the number of hours of food deprivation (e.g., Caraco et al., 1980), the size of the energy store available to the animal (e.g., Cartar \& Dill, 1990), the ambient temperature (Caraco et al., 1990), the size (e.g., Mazur, 1988) or concentration (Perez \& Waddington, 1996) of food, and so on. It has not usually been manipulated by altering rate of food availability (but see Ito et al., 2000) or time in session (but see Hastjarjo, Silberberg, \& Hursh, 1990), as was done in the present experiments.

\section{EXPERIMENT 1}

In Experiment 1, we examined the effect of rate of reinforcement and time in session on the preference for variability when subjects chose between FI and VI schedules.

Table 2

The Effect That Each of the Independent Variables Should Have on the Preference for Variability

\begin{tabular}{lllc}
\hline & \multicolumn{3}{c}{ Theory } \\
\cline { 2 - 4 } Independent Variable & \multicolumn{1}{c}{ Habituation } & RST & Scaling Theory and SET \\
\hline Time in session & stronger later & stronger earlier & no effect \\
Rate of reinforcement & stronger at higher & stronger at lower & no effect \\
\hline Note-RST, risk-sensitive models of optimal foraging theory; SET, scalar expectancy theory.
\end{tabular}




\section{Method}

Subjects. The subjects were 4 racing homer pigeons maintained at approximately $85 \%$ of their free-feeding body weights by supplemental feedings given after each subject had completed the experimental session. Two subjects were male (95 and 173) and 2 were female (1977 and 5504). All the subjects had prior experimental experience. Most recently, they had participated in a study that examined responding on concurrent FI VI schedules. In addition, Subject 5504 had participated in a multidimensional scaling of food preferences. The subjects were housed individually, had free access to water in their home cages, and were maintained on a 12:12-h light:dark cycle.

Apparatus. The apparatus was a three-key experimental enclosure for pigeons, measuring $35.5 \times 26.5 \times 29.5 \mathrm{~cm}$. The response keys were $2.5-\mathrm{cm}$-diameter Plexiglas panels, located $3.0 \mathrm{~cm}$ below the ceiling. The center key appeared in the middle of the panel, and the left and right keys were $7.5 \mathrm{~cm}$ from this key. A $4.5 \times 5.0 \mathrm{~cm}$ opening that allowed access to mixed grain was located $9.0 \mathrm{~cm}$ below the center key. The houselight was a $4.0-\mathrm{cm}$-diameter Plexiglas panel, $1.5 \mathrm{~cm}$ below the ceiling and $0.5 \mathrm{~cm}$ from the right edge of the panel. An $8.0-\mathrm{cm}$-diameter speaker also appeared $1.0 \mathrm{~cm}$ above the floor and $1.5 \mathrm{~cm}$ from the right edge of the panel. The experimental panel was housed in a sound-attenuating chamber. A ventilating fan masked noises from outside the chamber. Experimental events were programmed and data were recorded with an IBM-compatible computer running MED-Associates software. The computer was located in a different room from the experimental enclosure.

Procedure. The subjects were placed immediately on the experimental procedure, because they had previously pecked keys. The session began with the initial link, during which the lights on the left and center keys were illuminated. The left key was illuminated with red light; the center key was illuminated with white light. The subjects could peck either key at any time. When a VI 30-sec schedule timed out, the computer randomly selected either the left or the center terminal link to be presented. If the left terminal link was selected, a peck on the left key terminated the initial link and started the terminal link. If the center terminal link was selected, a peck on the center key terminated the initial link and began the terminal link. The left key was illuminated during the left terminal link. The center key was illuminated during the center terminal link. Pecking the illuminated key eventually produced a reinforcer; pecking the other key had no effect. In one terminal link, the reinforcer was scheduled according to an FI schedule. In the other terminal link, the reinforcer was scheduled according to a VI schedule that provided the same arithmetic mean interreinforcer interval as the FI schedule. The variable alternative occurred on the left key for 2 subjects and on the center key for the other 2 . The subjects returned to the initial link of the chain immediately after obtaining one reinforcer in the terminal link.

The schedules of reinforcement available in the terminal link varied across conditions. They were FI and VI 15-sec, FI and VI 105sec, FI and VI 45-sec, FI and VI 5-sec, and FI and VI 225-sec schedules in different conditions, conducted in that order. These particular schedules were chosen in order to provide a wide range of rates of reinforcement and to exceed the range that had been used in other studies to take animals from a positive to a negative energy budget (e.g., Ito et al., 2000). These schedules were also chosen because adding the average length of the initial link to the average length of these terminal links produced rates of reinforcement similar to those that had produced different amounts of habituation to the reinforcer in past studies (e.g., McSweeney, 1992). Reinforcer availability on all VI schedules was programmed according to a 25-interval Fleshler and Hoffman (1962) series.

Each experimental condition (terminal-link schedule) was presented for 30 sessions. The sessions were conducted daily, five or six times per week. All the sessions were $60 \mathrm{~min}$ long, excluding the time of reinforcer availability. The houselight was illuminated throughout the session. Reinforcers were $5 \mathrm{sec}$ of access to a maga- zine that contained mixed grain. The lights on the keys were turned off, and the hopper light was illuminated, during reinforcement.

\section{Results}

Table 3 (top) presents the session-average preference for variability for individual subjects and for the mean for all the subjects responding on each schedule of reinforcement. Throughout this study, preference for variability was calculated by averaging the number of responses in each initial link over the last five sessions for which each schedule was provided. Preference was then calculated by dividing the mean number of initial-link responses on the variable alternative by the mean number of total initiallink responses (constant plus variable). The result for the mean for all the subjects was calculated by determining the mean initial-and terminal-link responses for all the subjects and then using the mean to calculate a proportion. A preference greater than .5 indicates that the subject preferred the variable alternative. A preferences less than .5 indicates preference for the constant alternative. A 1.0 represents exclusive preference for the variable alternative.

We applied $t$ tests for matched pairs to the number of responses during the initial links associated with the FI and VI terminal links for each individual subject responding during the last five sessions for which each schedule was available. Asterisks appear in Table 3 when these tests were statistically significant $(p<.05)$. The $t$ tests were applied to number of responses, rather than to the proportional measures of preference, because proportions are bounded and may not be normally distributed. This was particularly true, in the present case, when preferences were close to the ceiling of 1.0 for some schedules.

Table 3

Session-Average Preferences for Variability (Initial-Link Responses for Variable Component/Total Initial-Link Responses) for Each Subject and for the Mean of All the Subjects Responding on Each Schedule of Reinforcement

\begin{tabular}{|c|c|c|c|c|c|}
\hline \multirow[b]{2}{*}{ Subject } & \multicolumn{5}{|c|}{ Schedule in Terminal Link } \\
\hline & $5 \mathrm{sec}$ & $15 \mathrm{sec}$ & $45 \mathrm{sec}$ & $105 \mathrm{sec}$ & $225 \mathrm{sec}$ \\
\hline \multicolumn{6}{|c|}{ Experiment 1} \\
\hline 95 & $.59 *$ & $.74 *$ & $.98 *$ & $.98 *$ & $.98 *$ \\
\hline 173 & $.56 *$ & .48 & $.71 *$ & $.99 *$ & $.99 *$ \\
\hline 1977 & $.73 *$ & $.63^{*}$ & $.98 *$ & $.98 *$ & $.98 *$ \\
\hline 5504 & .47 & $.78 *$ & $.83^{*}$ & $.98 *$ & $.96 *$ \\
\hline Mean & .58 & .62 & .86 & .98 & .98 \\
\hline \multicolumn{6}{|c|}{ Experiment 2} \\
\hline 38 & .53 & .49 & $.60 *$ & $.70 *$ & .58 \\
\hline 102 & .48 & .54 & .64 & .48 & $.62 *$ \\
\hline 405 & .54 & $.61 *$ & $.67 *$ & $.65^{*}$ & $.77 *$ \\
\hline 5706 & .42 & $.41 *$ & .50 & .46 & .52 \\
\hline Mean & .51 & .51 & .61 & .60 & .65 \\
\hline \multicolumn{6}{|c|}{ Experiment 3} \\
\hline 29 & $.25 *$ & $.26^{*}$ & $.17 *$ & $.33 *$ & $.31 *$ \\
\hline 103 & $.49 *$ & .47 & $.41^{*}$ & .43 & .72 \\
\hline 592 & $.72 *$ & .59 & .51 & $.60 *$ & $.69 *$ \\
\hline 911 & .41 & .42 & $.37 *$ & .53 & .48 \\
\hline Mean & .44 & .40 & .35 & .45 & .60 \\
\hline
\end{tabular}

*The number of initial-link responses were statistically significant $(p<$ $.05)$ for the constant and the variable alternatives. 
Table 3 shows that, in all but two cases, individual subjects preferred the VI to the FI schedule. All of the preferences for the variable schedule were statistically significant. This preference became stronger as the terminal link lengthened (higher VI requirement), and there was almost exclusive preference for the VI schedule with the two longest terminal links.

Figure 1 presents the preference for variability during successive 5-min intervals in the session for individual subjects and for the mean of all the subjects. Preferences were calculated as in Table 3, except that they were calculated over 5-min intervals, rather than over the session. Figure 1 shows that preference for the VI schedule did not change systematically within sessions. Instead, preference remained relatively constant, and any within-session changes that did occur were not consistent across schedules or subjects. A ceiling effect may have contributed to the relatively constant preferences with the VI 105-sec and VI 225-sec terminal links, but not with the other schedules.

The failure to find within-session changes in preference for variability might have occurred if habituation did not alter the rates of initial-link responding that entered into
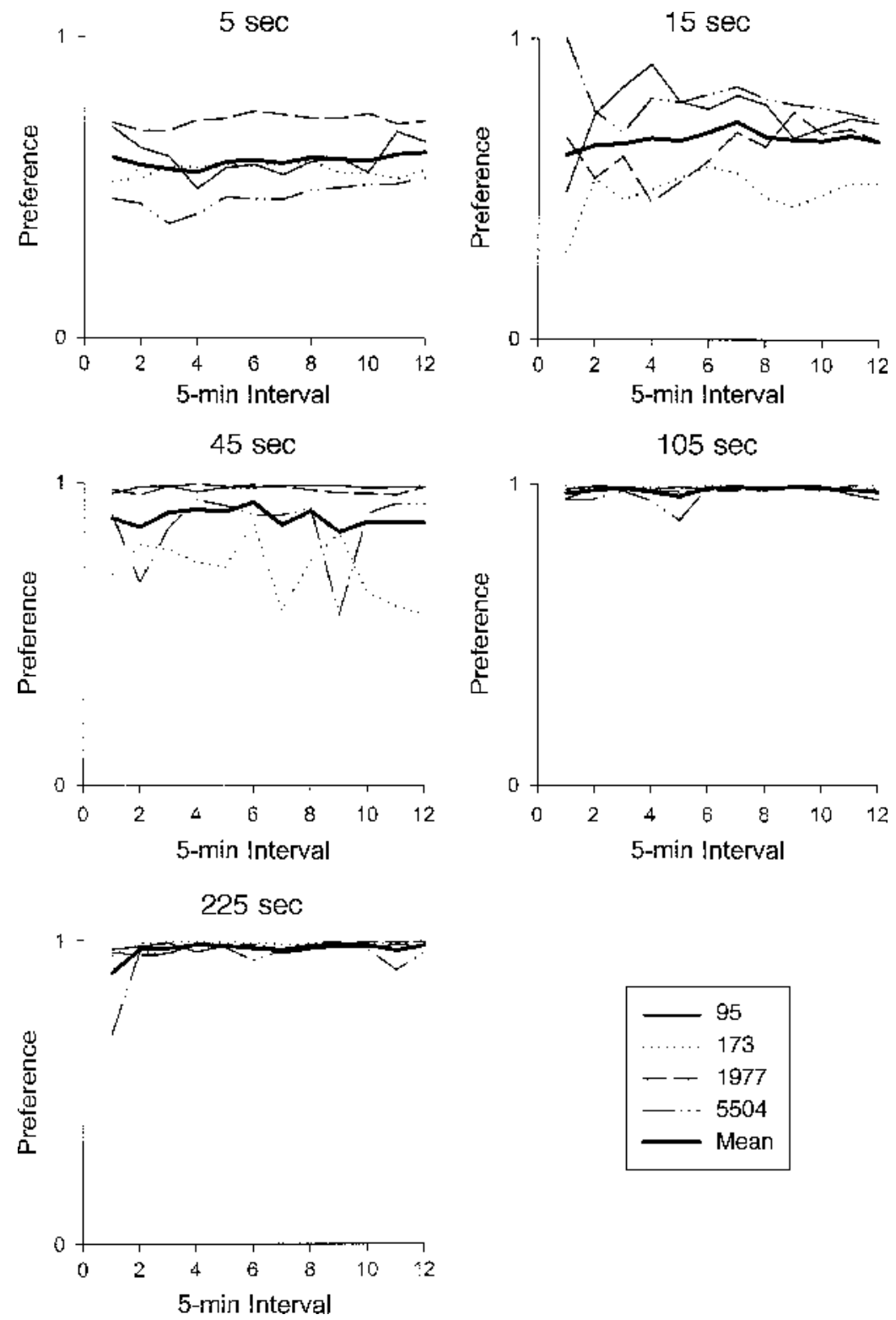

Figure 1. Preference for variability (variable/variable plus constant initial-link responses) during successive 5-min intervals in the session for the individual pigeons (thin lines) and for the mean for all the pigeons (thick line) in Experiment 1. Each graph presents the results for a different terminal link. 
the calculations of preference. If this were so, rate of initiallink responding would not change significantly within the session (e.g., McSweeney, Hinson, \& Cannon, 1996). To test this idea, one-way (5-min interval) repeated measures analyses of variance (ANOVAs) were applied to the number of initial-link responses during successive 5-min intervals in the session for each individual subject responding during the last 5 sessions for which each schedule was available. The results of these tests appear in Table 4 . Blanks appear in the table when the number of responses was too small to conduct an ANOVA. Degrees of freedom in the numerator that are less than 11 and degrees of freedom in the denominator that are less than 44 appear when a subject failed to respond during some 5-min intervals in the session. Table 4 shows that responding usually changed significantly within sessions for the initial links associated with both the FI and the VI terminal links when the terminal links provided high (5 or $15 \mathrm{sec}$ ), but not low (45, 105 , or $225 \mathrm{sec})$, rates of reinforcement.

Figures $2(5 \mathrm{sec})$ and $3(15 \mathrm{sec})$ present within-session changes in initial-link responding during the two schedules for which these changes were significant for most of the subjects. Proportions of total-session responses are plotted as a function of successive 5-min intervals in the session. Proportions were calculated by dividing the number of responses in an initial link during a 5-min interval by the total responses in that initial link during the session. Proportions were presented in order to normalize the withinsession patterns for differences in absolute response rates between the fixed and the variable alternatives. Figures 2 and 3 show that the form of the within-session response patterns differed for different subjects. Responding sometimes increased within the session (Subject 1977, 5-sec schedule), sometimes decreased within the session (Subject 95,15 -sec schedule), and sometimes increased and then decreased within the session (Subject 173, 5-sec schedule).

\section{EXPERIMENT 2}

In Experiment 2, we examined the effect of rate of reinforcement and time in session on the preference for variability when subjects chose between fixed and variable reinforcer delays.

\section{Method}

Subjects. The subjects were a different group of 4 racing homer pigeons. Two subjects were male (405 and 5706), and two were female (38 and 102). All the subjects had prior experimental experience. Most recently, 3 of the subjects $(102,405$, and 5706) had participated in a study in which probe preference tests were used to measure reinforcer value during multiple schedules. The subjects were housed and maintained as in Experiment 1.

Apparatus. The apparatus was a two-key experimental enclosure for pigeons, measuring $39.0 \times 33.0 \times 31.0 \mathrm{~cm}$. The two $2.5-\mathrm{cm}-$ diameter response keys appeared $22.0 \mathrm{~cm}$ above the floor and $12.0 \mathrm{~cm}$ apart. The left key was $11.5 \mathrm{~cm}$ from the left wall; the right key was $10.5 \mathrm{~cm}$ from the right wall. The left key could be illuminated with red light; the right key could be illuminated with white light. A $6.0 \times 5.0 \mathrm{~cm}$ opening allowed access to a magazine containing mixed grain. It was $5.5 \mathrm{~cm}$ above the floor and $17.0 \mathrm{~cm}$ from the right wall. A $3.0-\mathrm{cm}$-diameter houselight appeared $3.5 \mathrm{~cm}$ from the ceiling and $3.5 \mathrm{~cm}$ from the right wall. The experimental panel was housed in a sound-attenuating chamber. A ventilating fan masked noises from outside the chamber. Experimental events were programmed and data were recorded with an IBM-compatible computer running MED-Associates software. The computer was located in a different room from the experimental enclosure.

Procedure. The procedure was the same as that in Experiment 1, except that the links of the concurrent-chains schedule appeared on the left and right keys instead of on the left and center keys. In one terminal link (constant alternative), the reinforcer always occurred $5 \mathrm{sec}$ after the response that produced it. In the other terminal link (variable alternative), the reinforcer occurred at a variable delay of

Table 4

Results of One-Way (5-Min Interval) Repeated Measures Analyses of Variance Applied to the Number of Initial-Link Responses by Individual Pigeons During the Last Five Sessions for Which Each Schedule Was Available in Experiment 1

\begin{tabular}{clll}
\hline Schedule & Subject & Variable Interval Component & Fixed Interval Component \\
\hline $5 \mathrm{sec}$ & 95 & $F(11,44)=10.260, p<.001$ & $F(11,44)=8.964, p<.001$ \\
& 173 & $F(11,44)=2.473, p<.017$ & $F(11,44)=1.535, p<.154$ \\
& 1977 & $F(11,44)=3.618, p<.001$ & $F(11,44)=2.412, p<.019$ \\
& 5504 & $F(11,44)=6.130, p<.001$ & $F(11,44)=3.102, p<.004$ \\
$15 \mathrm{sec}$ & 95 & $F(11,44)=0.818, p<.623$ & $F(11,44)=3.713, p<.001$ \\
& 173 & $F(11,44)=2.757, p<.008$ & $F(11,44)=2.982, p<.005$ \\
& 1977 & $F(11,44)=5.326, p<.001$ & $F(11,44)=2.520, p<.015$ \\
& 5504 & $F(11,44)=2.590, p<.012$ & $F(9,36)=0.835, p<.589$ \\
$45 \mathrm{sec}$ & 95 & $F(11,44)=1.006, p<.457$ & $F(11,44)=1.118, p<.371$ \\
& 173 & $F(11,44)=1.088, p<.393$ & $F(11,44)=1.081, p<.398$ \\
& 1977 & $F(11,44)=1.557, p<.146$ & $F(11,44)=1.429, p<.194$ \\
& 5504 & $F(11,44)=0.522, p<.878$ & $F(11,44)=0.985, p<.474$ \\
$105 \mathrm{sec}$ & 95 & $F(11,44)=0.931, p<.521$ & $F(11,44)=1.959, p<.057$ \\
& 173 & $F(11,44)=0.492, p<.898$ & $F(11,44)=0.426, p<.936$ \\
& 1977 & $F(11,44)=0.990, p<.470$ & $F(11,44)=0.581, p<.834$ \\
$225 \mathrm{sec}$ & 5504 & $F(10,40)=2.443, p<.022$ & $F(7,28)=0.678, p<.689$ \\
& 95 & $F(11,44)=1.089, p<.392$ & $F(11,44)=0.619, p<.802$ \\
& 173 & $F(11,44)=1.203, p<.313$ & \\
& 1977 & $F(11,44)=1.389, p<.212$ & \\
& 5504 & $F(11,44)=0.513, p<.884$ & $F(11,44)=1.020, p<.445$ \\
\hline
\end{tabular}



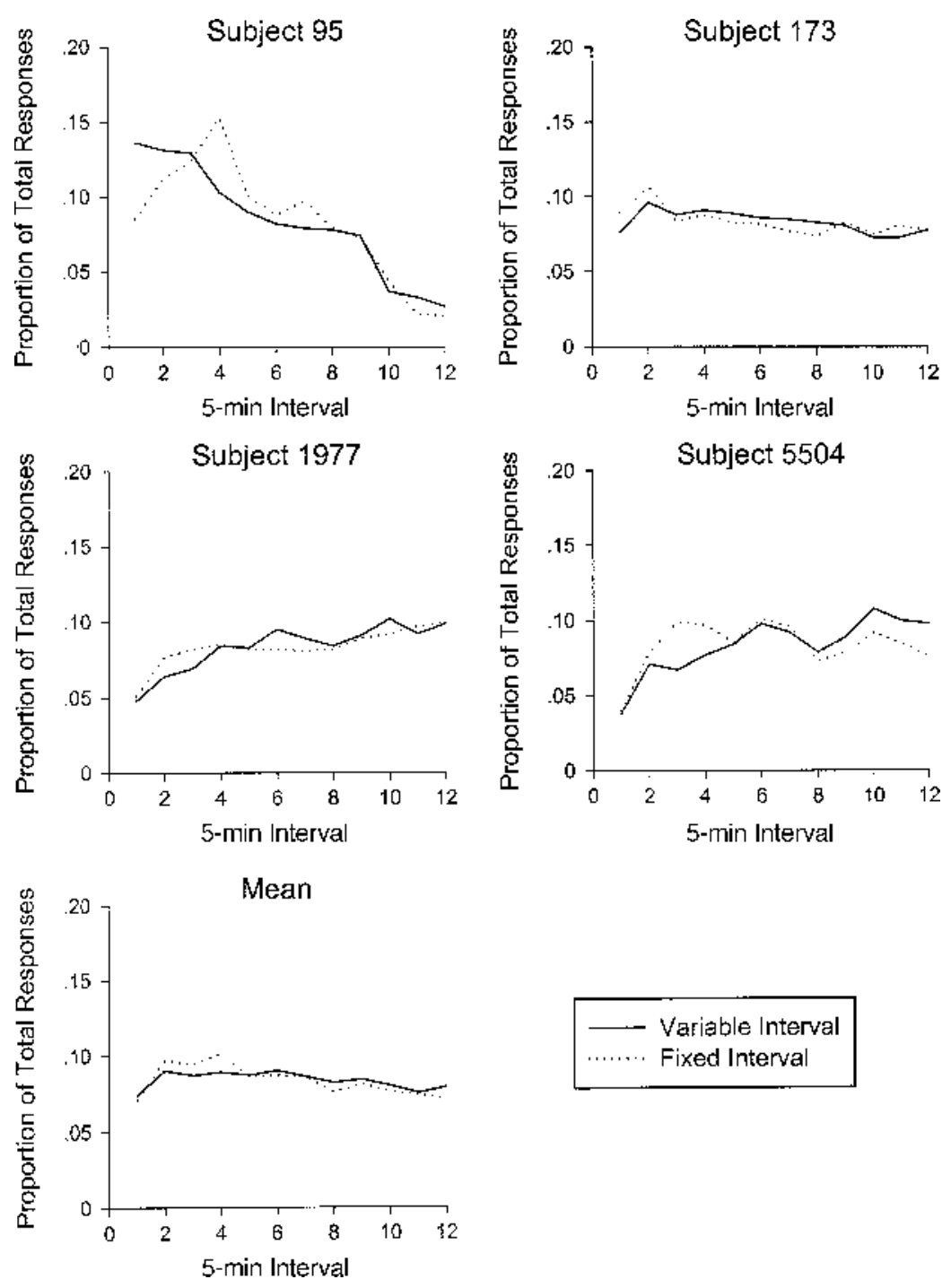

Figure 2. Proportion of total responses during successive 5-min intervals in the session for the variable (solid line) and the fixed (dashed line) initial-link components in Experiment 1 when the terminal link provided a variable interval 5-sec schedule. Each graph presents the results for an individual pigeon or for the mean for all the pigeons.

$1,3,5,7$, or $9 \mathrm{sec}$, determined randomly. During the delay to reinforcement, the light on the key associated with the terminal link was extinguished. Because pigeons rarely peck unlighted keys, this helped to ensure that the obtained delay between responding and reinforcement was close to the scheduled delay. Again, the variable delay to reinforcement occurred on the left key for 2 subjects and on the right key for the other 2 . The schedule of reinforcement was the same for both terminal links and varied across conditions. The reinforcer was available according to the following terminal-link schedules, presented in the following order: VI 15-sec, VI 45-sec, VI 105sec, VI 225-sec, and VI 5-sec.

\section{Results}

Table 3 (middle) presents the session-average preference for variability for individual subjects and for the mean for all the subjects responding on each schedule of reinforcement. The results were calculated and presented as in Experiment 1. Again, $t$ tests for matched pairs determined whether initial-link responding differed significantly for the constant and the variable alternatives for individual subjects. The subjects were relatively indifferent to the constant and the variable alternatives when the terminal links were short (VI 5-sec or VI 15-sec). In both cases, 2 subjects preferred the variable alternative, 2 preferred the constant alternative, and these apparent preferences were often not statistically significant. Stronger preferences, and preferences that were more likely to be statistically significant, developed as the terminal links became longer. All the subjects showed an apparent preference for vari- 

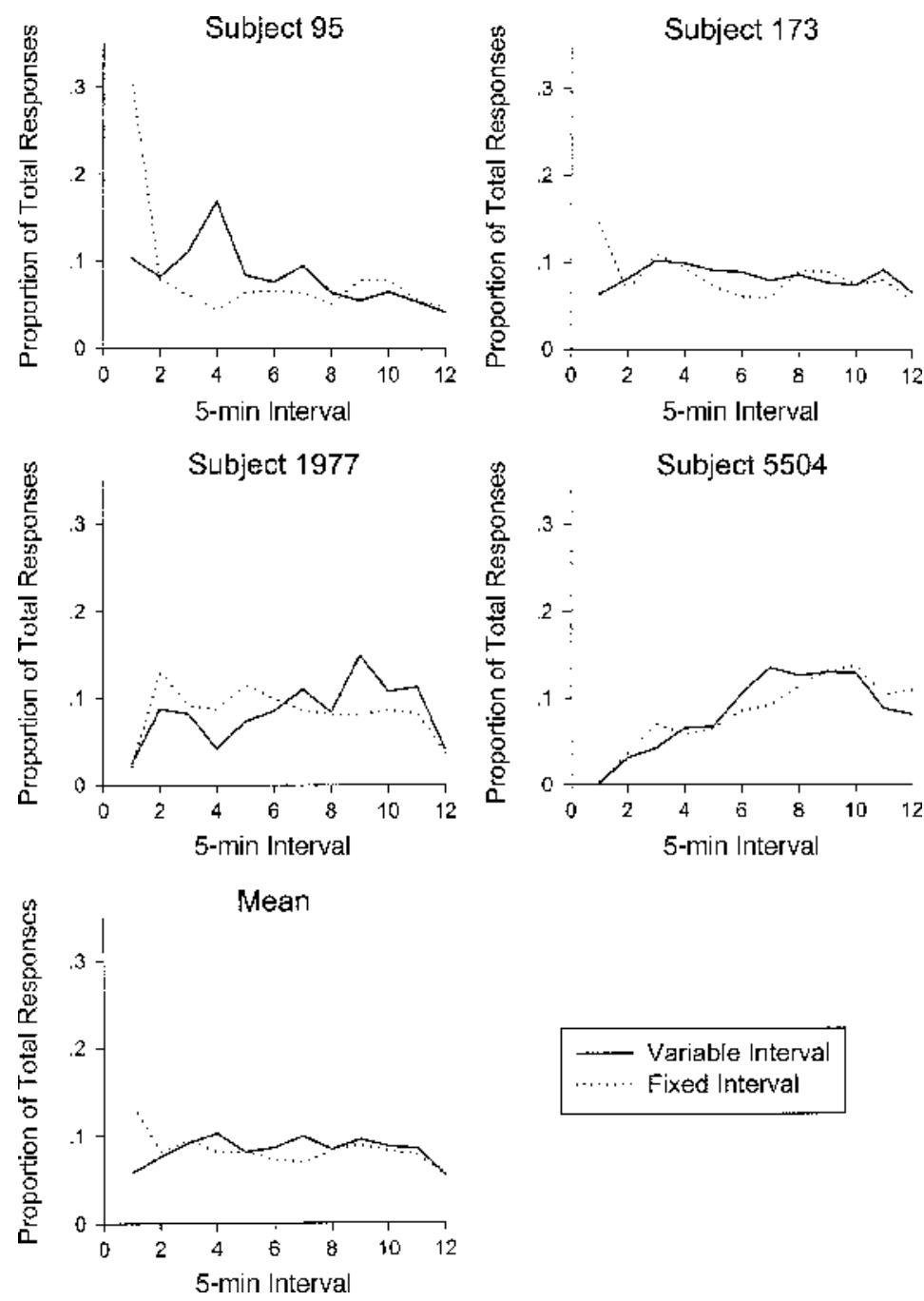

Figure 3. Proportion of total responses during successive 5-min intervals in the session for the variable (solid line) and the fixed (dashed line) initial-link components in Experiment 1 when the terminal link provided a variable interval 15-sec schedule. Each graph presents the results for an individual pigeon or for the mean for all the pigeons.

ability, and preferences were larger during the longest terminal link (VI 225-sec) than during shorter links. However, even these preferences were statistically significant for only 2 subjects.

Figure 4 presents the preference for variability during successive 5-min intervals in the session for individual subjects and for the mean for all the subjects. The results were calculated and presented as for Figure 1. Figure 4 shows that preferences for variability did not change systematically within the session. Instead, any changes that did occur were not consistent across schedules or subjects.

Table 5 presents the results of one-way (5-min interval) repeated measures ANOVAs that were applied to the number of initial-link responses during successive 5-min intervals in the session for each individual subject respond- ing during the last five sessions for which each schedule was available. Table 5 shows that responding usually changed significantly within sessions for both the variable and the constant initial links when the schedules provided high (VI 5-sec, VI 15-sec), but not lower (VI 45sec, VI 105-sec), rates of reinforcement. Significant within-session changes in responding also occurred for 2 subjects responding at the lowest rate of reinforcement (VI 225-sec).

Figures $5(5 \mathrm{sec})$ and $6(15 \mathrm{sec})$ present the withinsession changes in responding during the two schedules for which these changes were usually significant. The results were calculated and presented as for Figures 2 and 3. Figures 5 and 6 show that responding usually increased and then decreased within the session, but 1 subject showed 

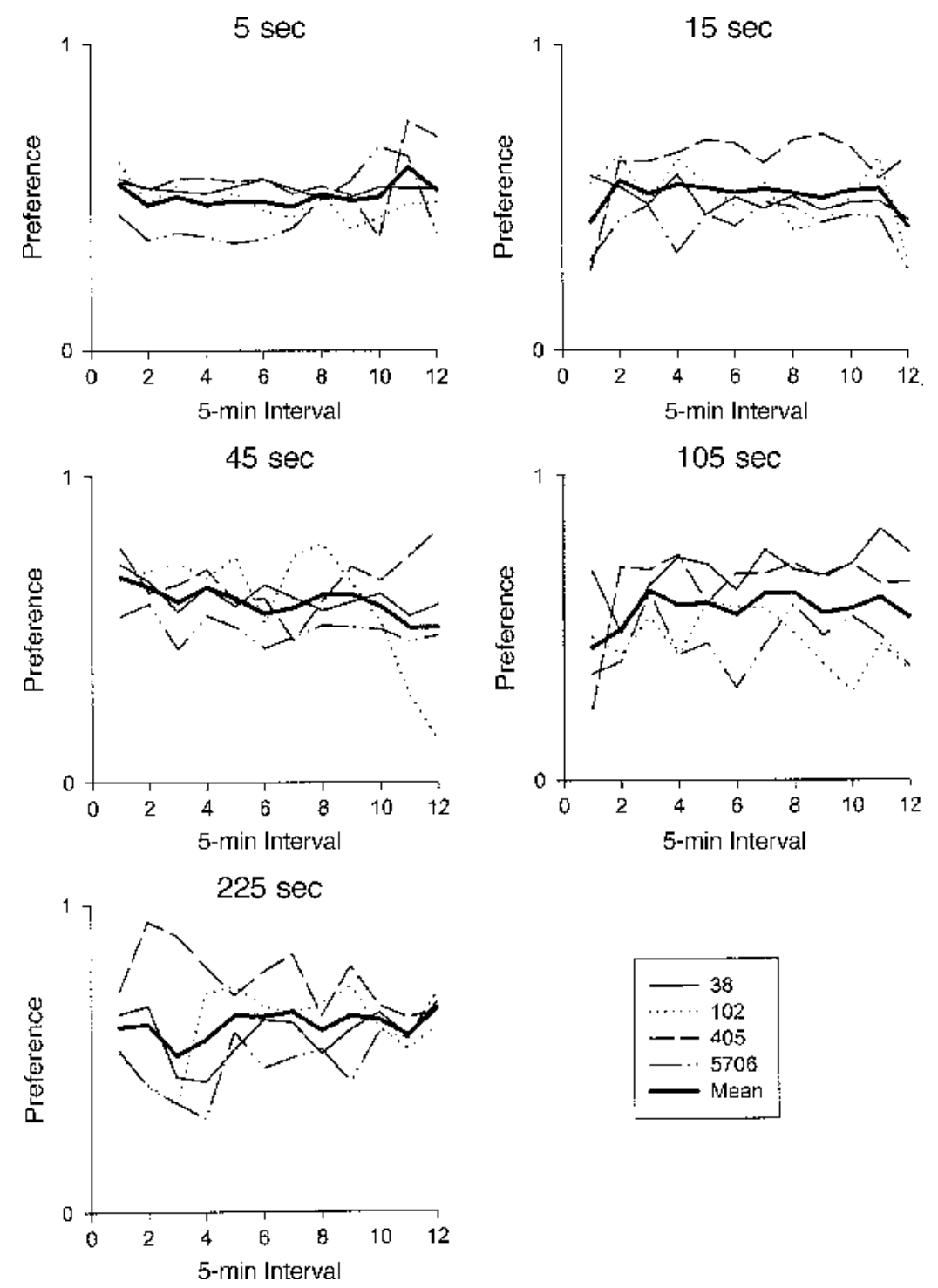

Figure 4. Preference for variability (variable/variable plus constant initial-link responses) during successive 5 -min intervals in the session for the individual pigeons (thin lines) and for the mean for all the pigeons (thick line) in Experiment 2. Each graph presents the results for a different terminal link.

a predominantly decreasing pattern (Subject 5706, VI 5sec schedule).

\section{EXPERIMENT 3}

In Experiment 3, we examined the effect of rate of reinforcement and time in session on the preference for variability when the subjects chose between fixed and variable reinforcer durations.

\section{Method}

Subjects. The subjects were a third group of 4 racing homer pigeons that were housed and maintained as in Experiments 1 and 2. Three subjects were male $(29,103$, and 911), and one was female (592). All the subjects had prior experimental experience. Most re- cently, all had responded on concurrent schedules. Three subjects (29, 103, and 592) had also responded on multiple schedules, and one (911) had participated in a multidimensional scaling of food preferences.

Apparatus and Procedure. The apparatus was the same as that used in Experiment 2. The procedure was similar to that used in Experiments 1 and 2, with the following exceptions. As in Experiment 2, the initial and terminal links appeared on the left and right keys. Reinforcement for the variable terminal link was $1,3,5,7$, or $9 \mathrm{sec}$ of access to mixed grain, determined randomly. Reinforcement for the other terminal link was always a constant, 5-sec access to mixed grain. Again, the variable terminal link appeared on the left key for 2 subjects and on the right key for the other 2 . The subjects responded on the following terminal-link schedules presented in the following order: VI 15-sec, VI 45-sec, VI 225-sec, VI 5-sec, and VI 105-sec. 
Table 5

\begin{tabular}{|c|c|c|c|}
\hline Schedule & Subject & Variable Delay & Constant Delay \\
\hline \multirow[t]{4}{*}{$5 \mathrm{sec}$} & 38 & $F(11,44)=3.198, p<.003$ & $F(11,44)=2.353, p<.022$ \\
\hline & 102 & $F(11,44)=2.943, p<.005$ & $F(11,44)=3.255, p<.003$ \\
\hline & 405 & $F(11,44)=11.351, p<.001$ & $F(11,44)=9.463, p<.001$ \\
\hline & 5706 & $F(11,44)=5.683, p<.001$ & $F(11,44)=18.905, p<.001$ \\
\hline \multirow[t]{4}{*}{$15 \mathrm{sec}$} & 38 & $F(11,44)=0.329, p<.975$ & $F(11,44)=1.045, p<.425$ \\
\hline & 102 & $F(11,44)=2.768, p<.008$ & $F(11,44)=2.157, p<.035$ \\
\hline & 405 & $F(11,44)=1.637, p<.122$ & $F(11,44)=2.362, p<.022$ \\
\hline & 5706 & $F(11,44)=4.222, p<.001$ & $F(11,44)=2.182, p<.033$ \\
\hline \multirow[t]{4}{*}{$45 \mathrm{sec}$} & 38 & $F(11,44)=0.470, p<.912$ & $F(11,44)=0.874, p<.571$ \\
\hline & 102 & $F(11,44)=1.273, p<.272$ & $F(11,44)=0.490, p<.900$ \\
\hline & 405 & $F(11,44)=1.831, p<.077$ & $F(11,44)=1.587, p<.136$ \\
\hline & 5706 & $F(11,44)=0.537, p<.868$ & $F(11,44)=0.339, p<.972$ \\
\hline \multirow[t]{4}{*}{$105 \mathrm{sec}$} & 38 & $F(11,44)=1.173, p<.333$ & $F(11,44)=1.098, p<.386$ \\
\hline & 102 & $F(11,44)=1.252, p<.283$ & $F(11,44)=1.511, p<.162$ \\
\hline & 405 & $F(11,44)=0.737, p<.698$ & $F(11,44)=0.943, p<.510$ \\
\hline & 5706 & $F(11,44)=1.170, p<.335$ & $F(11,44)=0.871, p<.574$ \\
\hline \multirow[t]{4}{*}{$225 \mathrm{sec}$} & 38 & $F(11,44)=1.460, p<.181$ & $F(11,44)=1.170, p<.335$ \\
\hline & 102 & $F(11,44)=0.657, p<.770$ & $F(11,44)=0.298, p<.983$ \\
\hline & 405 & $F(11,44)=2.219, p<.031$ & $F(11,44)=2.949, p<.005$ \\
\hline & 5706 & $F(11,44)=2.440, p<.018$ & $F(11,44)=2.305, p<.025$ \\
\hline
\end{tabular}

\section{Results}

Table 3 (bottom) presents session-average preferences for variability for individual subjects and for the mean for all the subjects responding on each schedule of reinforcement. The results were calculated and presented as in Experiment 1. Again, a $t$ test for matched pairs determined whether initial-link responding differed significantly for the constant and the variable alternatives for individual subjects. The subjects differed in their preferences in this experiment. One subject showed a consistent preference for variability (592), 1 showed a consistent preference for constancy (29), and 1 was relatively indifferent (911). Subject 103 showed a preference for constancy when the components were short, which changed to a marginally significant preference for variability $[t(4)=2.408, p<.074]$ for the longest terminal link.

Figure 7 presents the preference for variability during successive 5-min intervals in the session for the individual subjects and for the mean for all the subjects. The results were calculated and presented as in Figure 1. Figure 7 shows that preferences for variability did not change systematically within the session. Rather, any changes in preference that did occur were not consistent across schedules or subjects.

Table 6 presents the results of one-way (5-min interval) repeated measures ANOVAs applied to the number of initial-link responses during successive 5-min intervals in the session for each individual subject responding during the last five sessions for which each schedule was available. Again, a blank appears in the table when the number of responses was too small to conduct an ANOVA. Table 6 shows that responding sometimes changed significantly within sessions during the schedule that provided the highest (VI 5-sec), but not lower (VI 45-sec, VI 105-sec,
VI 225-sec), rates of reinforcement. Results were less likely to be significant as rate of reinforcement decreased.

Figure 8 presents within-session changes in initial-link responding during the schedule (VI 5-sec) for which these changes were often significant. Results were calculated and presented as in Figures 2 and 3. Figure 8 shows that responding usually increased and then decreased within sessions.

\section{GENERAL DISCUSSION}

The present results are generally consistent with those of past the studies. Consistent with studies reported in Table 1, Experiments 1 and 2 showed that the subjects often preferred a variable to a constant outcome when variability was introduced either in the time between successive reinforcers (Experiment 1) or in the delay between a reinforcer and the response that produced it (Experiment 2). This preference for variability either was weaker or did not occur when the subjects chose between outcomes that differed in variability of size (Experiment 3 ). Also, consistent with the results of past studies of responding on simple (McSweeney, Roll, \& Weatherly, 1994), multiple (McSweeney, 1992; McSweeney, Roll, \& Cannon, 1994), and concurrent (McSweeney, Weatherly, \& Swindell, 1996) schedules, all three of the present experiments sometimes showed significant within-session changes in initial-link responding. As in the past studies, these within-session changes in responding were often shown for schedules that provided high, but not low, rates of reinforcement.

Finding results that were consistent with those in past studies is interesting because the procedure used in the present experiments was somewhat unusual. The same 

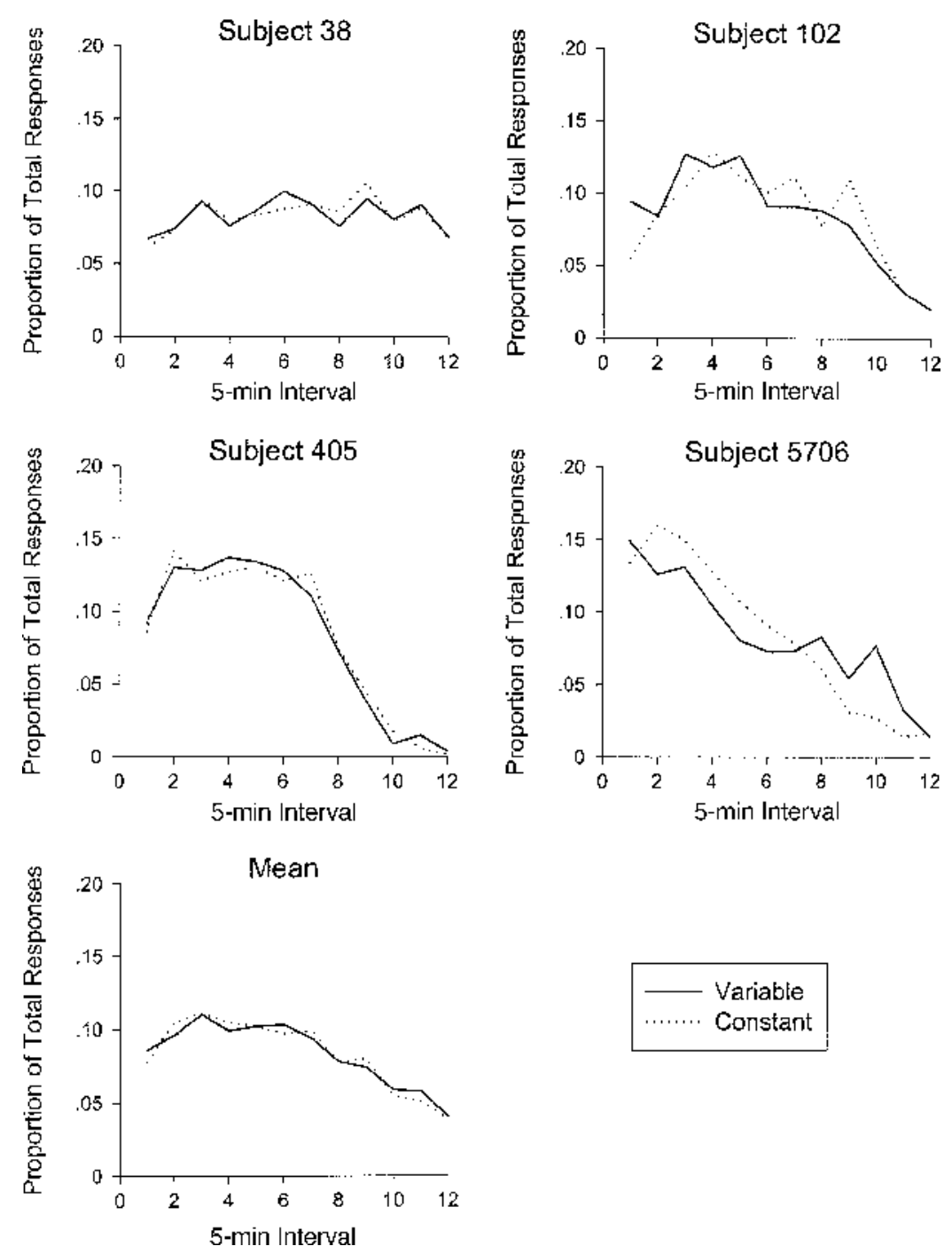

Figure 5. Proportion of total responses during successive 5-min intervals in the session for the variable (solid line) and constant (dashed line) initial-link components in Experiment 2 when the terminal link provided a variable interval 5 -sec schedule. Each graph presents the results for an individual pigeon or for the mean for all the pigeons.

stimuli signaled both the initial and the terminal links. Studies that employ concurrent-chains procedures often use different stimuli to signal these links. The procedure used here was dictated by equipment limitations. Nevertheless, the present experiments showed that the results found in other studies were strong enough to survive this procedural change.

On the surface, finding a preference for variability in Experiments 1 and 2, but not in Experiment 3, supports SET and scaling theories. As was argued earlier, these theories predict a preference for variability when the better alternative is indicated by a smaller, rather than a larger, number (e.g., interreinforcer interval or delay to reinforcement; Experiments 1 and 2). They predict a preference for constancy when the better alternative is indicated by a larger, rather than a smaller, number (e.g., amount of reinforcement; Experiment 3). The other theories do not make this prediction.

A difference in results across the present experiments should be interpreted with caution, however. To begin with, a position (or color) bias may have contributed to the weaker preference for variability observed in Experiment 3. Animals in our laboratory are usually biased away from the operandum located closer to the entrance to the chamber. Pigeons 29 and 911, who showed the greatest risk aversion in Experiment 3, also had the variable alternative on the key located closer to the entrance. However, position (or color) bias probably cannot entirely explain the difference among the experiments. Two subjects in Experiments 1 and 2 also had the variable alternative on the key 

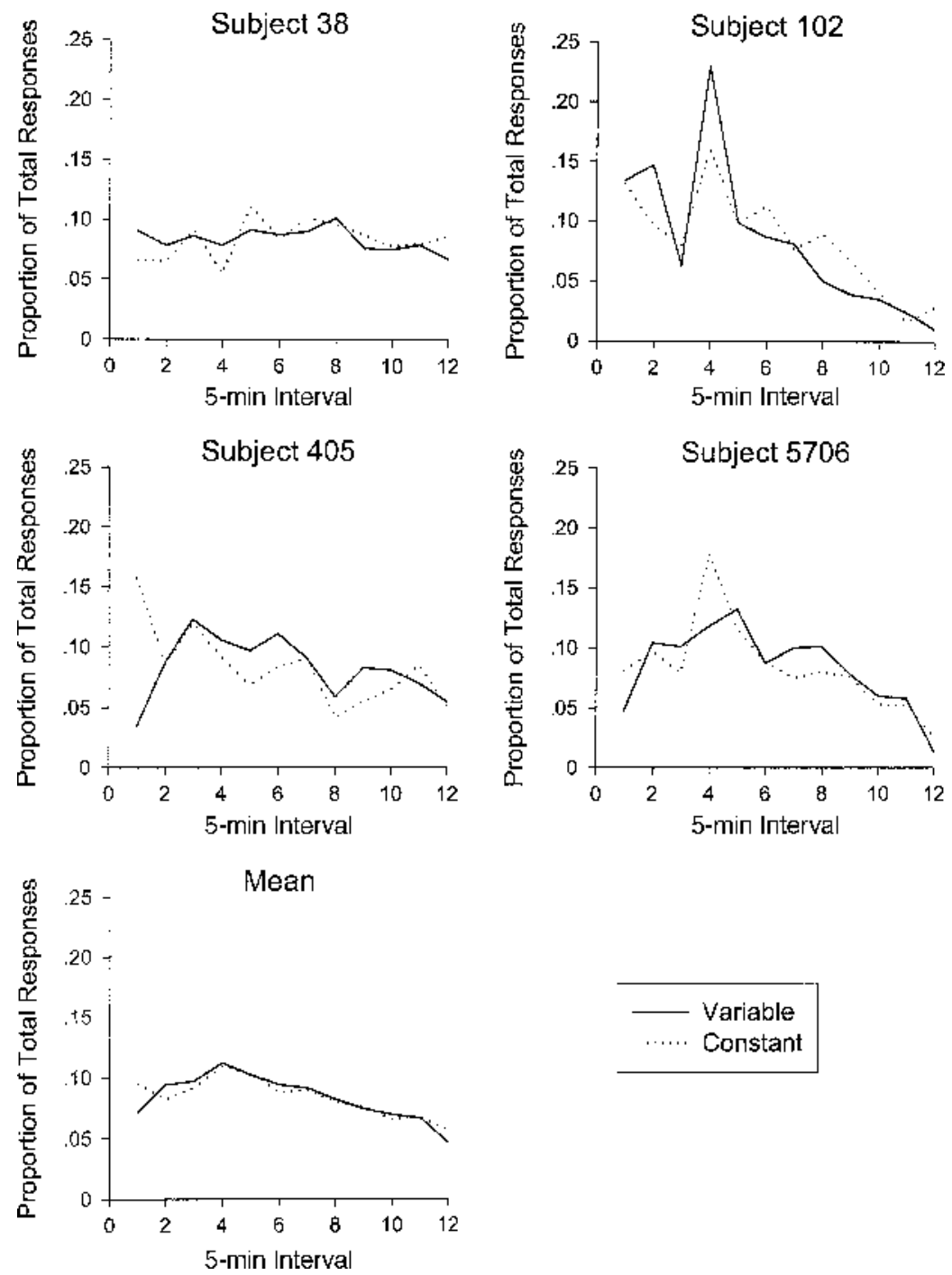

Figure 6. Proportion of total responses during successive 5-min intervals in the session for the variable (solid line) and the constant (dashed line) initial-link components in Experiment 2 when the terminal link provided a variable interval 15-sec schedule. Each graph presents the results for an individual pigeon or for the mean for all the pigeons.

closer to the entrance to the chamber, but avoidance of this key did not eliminate their preference for variability.

Another problem in comparing results across studies is that we cannot assume that the size of the difference between the variable and the constant outcomes was the same in all three experiments. The weaker preferences for variability (but not the preferences for constancy) in Experiment 3 might have resulted from a smaller difference between the variable and the constant alternatives in that experiment than in Experiments 1 and 2. Weaker preferences might be particularly likely in Experiment 3 because responding for fixed and variable hopper durations was compared. Controlling hopper duration does not pre- cisely control the amount of grain consumed, probably the true independent variable for the subject.

The present experiments supported two new conclusions about preference for variability. First, preference for variability did not change systematically within experimental sessions. Second, preferences were small and did not occur for some subjects when the terminal links were relatively short (VI 5-sec and VI 15-sec). Preferences were stronger and more consistent across subjects when terminal links were relatively long (VI 45 -sec, VI 105-sec, and VI 225-sec). Greater preferences have been reported, in the past, for longer than for shorter terminal links (e.g., MacEwen, 1972; Williams \& Fantino, 1978), but not when 
$5 \mathrm{sec}$

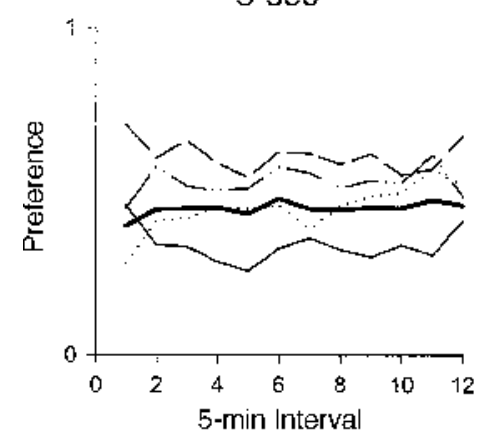

$45 \mathrm{sec}$
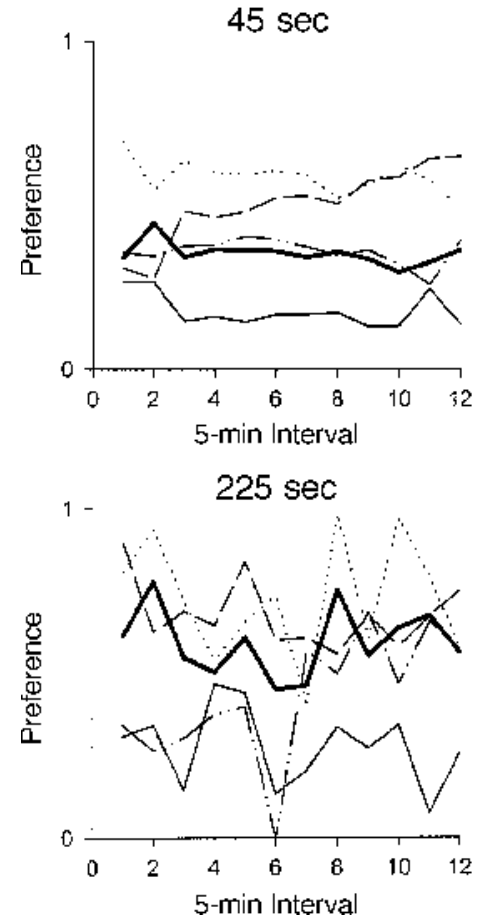

$15 \mathrm{sec}$

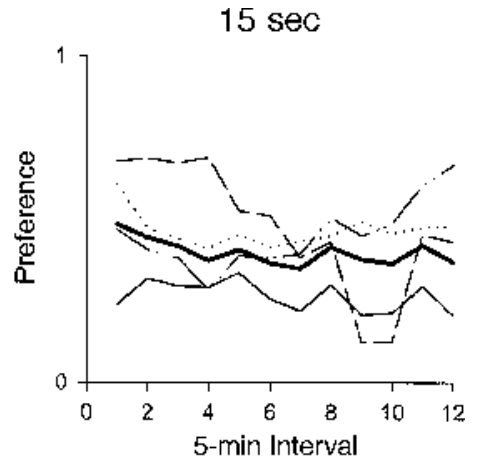

$105 \mathrm{sec}$
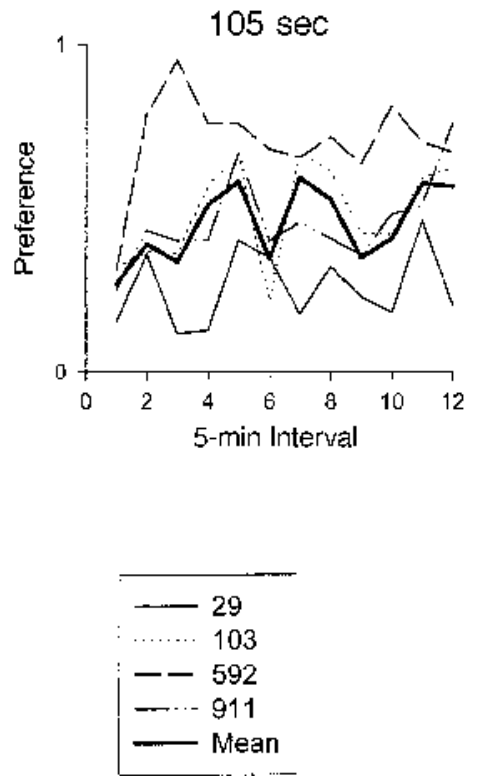

Figure 7. Preference for variability (variable/variable plus constant initiallink responses) during successive 5-min intervals in the session for the individual pigeons (thin lines) and for the mean for all the pigeons (thick line) in Experiment 3. Each graph presents the results for a different terminal link.

subjects chose between fixed and variable delays between a response and a reinforcer (Experiment 2 ) or between fixed and variable amounts of reinforcement (Experiment 3).

These two new findings are inconsistent with all of the explanations for the preference for variability that were described earlier. Scaling theories and SET correctly predicted that the preference for variability would not change within sessions, but they failed to predict that the preference for variability would usually be greater at lower (longer terminal links) than at higher (shorter terminal links) rates of reinforcement. In contrast, some versions of RST correctly predicted that preference for variability would be greater at lower than at higher rates of reinforcement but failed to predict that the preference for variability would remain constant within the session.
The present results might be reconciled with RST by arguing that the change in food deprivation that occurred with changes in rate of reinforcement was large enough to alter the subject's energy budget but that the change in deprivation that occurred within the session was not. Although such an assumption is post hoc, it is somewhat plausible. Even with this assumption, however, the present results provide only weak support for RST. Other theories are equally or more consistent with the results. For example, several general theories of performance on concurrentchains schedules predict stronger preferences for longer than for shorter terminal links. They also provide no reason to expect that preference will change systematically within sessions-for example, the contextual-choicemodel (CCM; e.g., Grace, 1994, 1996), delay reduction theory 
Table 6

Results of One-Way (5-min Interval) Repeated Measures Analysis of Variance Applied to the Number of Initial-Link Responses by Individual Pigeons During the Last Five Sessions for Which Each Schedule Was Available in Experiment 3

\begin{tabular}{clcc}
\hline Schedule & Subject & Variable Amount & Constant Amount \\
\hline $5 \mathrm{sec}$ & 29 & $F(11,44)=0.795, p<.644$ & $F(11,44)=3.600, p<.001$ \\
& 103 & $F(11,44)=1.767, p<.090$ & $F(11,44)=5.068, p<.001$ \\
& 592 & $F(11,44)=1.850, p<.074$ & $F(11,44)=2.002, p<.051$ \\
$15 \mathrm{sec}$ & 911 & $F(11,44)=7.342, p<.001$ & $F(11,44)=6.921, p<.001$ \\
& 29 & $F(11,44)=0.683, p<.747$ & $F(11,44)=0.574, p<.839$ \\
& 103 & $F(11,44)=3.256, p<.003$ & $F(11,44)=1.622, p<.126$ \\
& 592 & $F(11,44)=2.617, p<.012$ & $F(11,44)=2.294, p<.025$ \\
$45 \mathrm{sec}$ & 911 & $F(11,44)=1.078, p<.400$ & $F(11,44)=5.425, p<.001$ \\
& 29 & $F(11,44)=0.744, p<.691$ & $F(11,44)=1.359, p<.226$ \\
& 103 & $F(11,44)=0.454, p<.921$ & $F(11,44)=0.644, p<.781$ \\
& 592 & $F(11,44)=0.761, p<.675$ & $F(11,44)=1.966, p<.056$ \\
$105 \mathrm{sec}$ & 911 & $F(11,44)=2.769, p<.008$ & $F(11,44)=3.252, p<.003$ \\
& 29 & $F(11,44)=1.116, p<.372$ & $F(11,44)=2.114, p<.039$ \\
& 103 & $F(11,44)=0.834, p<.608$ & $F(11,44)=1.717, p<.101$ \\
$225 \mathrm{sec}$ & 592 & $F(11,44)=1.152, p<.347$ & $F(11,44)=0.780, p<.658$ \\
& 911 & $F(11,44)=0.790, p<.649$ & $F(11,44)=1.688, p<.108$ \\
& 29 & $F(11,44)=1.155, p<.345$ & $F(11,44)=0.499, p<.893$ \\
& 103 & $F(11,44)=0.741, p<.694$ & $F(11,44)=1.654, p<.117$ \\
& 592 & $F(11,44)=0.529, p<.873$ & $F(11,44)=0.446, p<.925$ \\
& 911 & & $F(11,44)=1.359, p<.226$ \\
\hline
\end{tabular}

(e.g., Fantino, 1969), and the hyperbolic value-added model (HVA; e.g., Mazur, 2001). The CCM and the HVA specifically predict the results of Experiment 1, and extensions of these theories could potentially predict the results of all the present experiments.

A simple experiment could pit the predictions of RST against the predictions of the more general models of concurrent-chains performance. Such an experiment would vary rate of reinforcement by changing initial-link duration. The models of concurrent-chains performance predict that preferences should increase with decreases in the length of the initial component, as has usually been found (e.g., Fantino, 1969; Fantino \& Davison, 1983). Some versions of RST (i.e., those that apply to the type of subjects used in the experiment) predict the opposite.

The results of these experiments are inconsistent with the idea that habituation to the reinforcer contributes to the preference for variability. If habituation had contributed, preferences should have been stronger, rather than weaker, at higher than at lower rates of reinforcement. Preferences should have also been larger later in the session than earlier. The failure of habituation theory did not occur because habituation to the reinforcer failed to influence initial-link responding and, therefore, the preference for variability. Within-session changes in initial-link responding were observed for the schedules that provided high rates of reinforcement in all the experiments. If such within-session changes in responding are produced partly by habituation to the reinforcers (McSweeney, Hinson, \& Cannon, 1996), then habituation did occur during the present experiments, at least when the terminal links were short. Nevertheless, a strong preference for variability did not develop for these short terminal links.

One potential explanation for the failure of habituation theory is that the effect of habituation was overridden by the terminal-link effect. As was argued earlier, initial-link preferences increase with increases in the duration of the terminal link (e.g., MacEwen, 1972; Williams \& Fantino, 1978). An increase in terminal-link duration was confounded with a decrease in reinforcement rate in the present experiments. Therefore, the decrease in preference for variability with an increasing rate of reinforcement predicted by the terminal-link effect may have obscured the increase in preference for variability with an increasing rate of reinforcement predicted by habituation theory. This idea could be tested by holding the terminal link constant and altering the rate of reinforcement by varying the length of an intertrial interval (ITI) between the end of one terminal link and the beginning of the next initial link. This was not done in the present experiments because most concurrent-chains procedures do not use ITIs.

A more likely explanation for the failure of habituation theory may be that all mixed grain reinforcers, regardless of their source, contribute to a single number that represents the total amount of habituation to mixed grain. Because habituation to the reinforcer was pooled across the fixed and variable alternatives, differential habituation to the reinforcer for these alternatives could not contribute to the preference for variability. Such an explanation is consistent with the relatively similar within-session patterns of responding for the two initial links of the present concurrentchains schedules (Figures 2, 3, 5, 6, and 8). Similar withinsession patterns would occur if both of those patterns were determined by a single number that represented the total amount of habituation. The explanation is also consistent with the results of past research about responding on concurrent schedules. The parameters and fit of the generalized matching law (GML; Baum, 1974) do not change systematically within sessions when subjects respond on concurrent schedules that provide qualitatively similar re- 

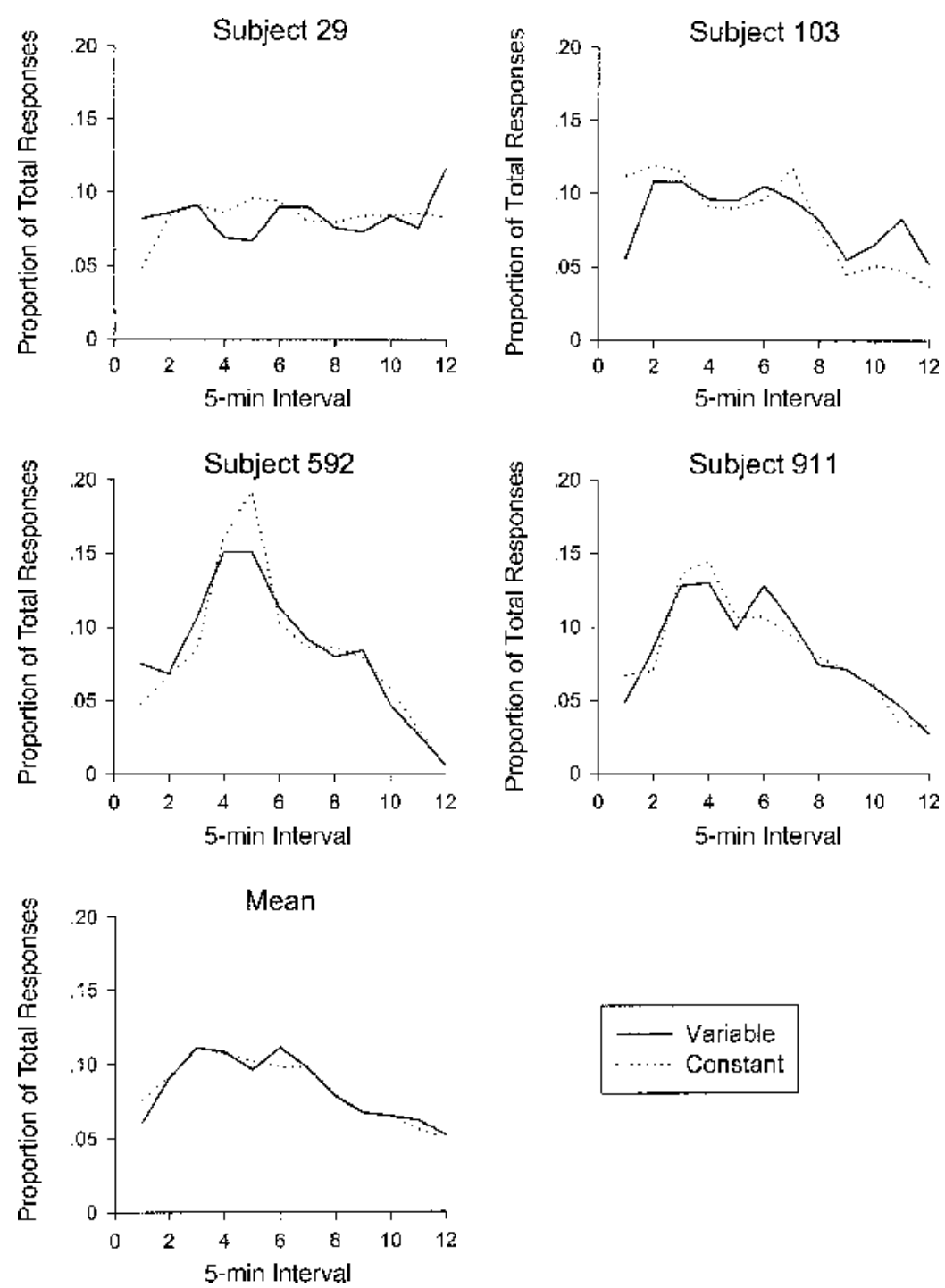

Figure 8. Proportion of total responses during successive 5-min intervals in the session for the variable (solid line) and the constant (dashed line) initial-link components in Experiment 3 when the terminal link provided a variable interval 5-sec schedule. Each graph presents the results for an individual pigeon or for the mean for all the pigeons.

inforcers in the two components. This conclusion holds regardless of whether the reinforcers for the two components are provided by similar (McSweeney, Weatherly, \& Swindell, 1996) or different (McSweeney, Weatherly, \& Roll, 1995) operanda and by similar (e.g., McSweeney, Weatherly, \& Swindell, 1996) or different (McSweeney, Murphy, \& Kowal, 2001; McSweeney, Swindell, \& Weatherly, 1999) simple schedules. The conclusion breaks down only when the components provide qualitatively different reinforcers (e.g., food and water; McSweeney, Swindell, \& Weatherly, 1996).

Finding that the parameters and fit of the GML do not change within sessions is consistent with the idea that within-session changes in responding are produced by a factor that contributes multiplicatively with other reinforcer variables to the overall value of the reinforcer. On the assumption that this multiplicative factor is the same for both components of the concurrent schedule as long as those components provide the same types of reinforcers (e.g., both provide mixed grain), the multipliers would cancel when ratios of response rates are calculated to fit the GML. The idea of similar multipliers for the two components of concurrent schedules is, in turn, consistent with McSweeney, Weatherly, and Swindell's (1996) conclusion that within-session patterns of responding during both components of a concurrent schedule are governed by ap- 
proximately the sum of the reinforcers obtained from the two components. The sum of reinforcers would be similar for both components, yielding similar within-session patterns of responding.

If this argument is correct, it may have important implications for theories of choice. It implies that habituation to the reinforcer is represented differently than other variables related to reinforcement. For example, Baum (1974) argued that aspects of the reinforcers, such as their rate of delivery, their size, and their immediacy, should be represented separately for the two components of a concurrent schedule in the GML. The present results showed that these aspects of terminal-link reinforcement should also be represented separately in theories of concurrent-chains performance. That is, the subjects responded differently in the initial links of concurrent-chains schedules (see Table 3) when their associated terminal links provided different schedules (Experiment 1), different delays to reinforcement (Experiment 2), and different amounts of reinforcement (Experiment 3). As a result, theories of concurrent-chains responding must also contain separate variables to represent the schedules, delays to reinforcement, and sizes of reinforcers delivered in each terminal link. In contrast, the present argument suggests that information about habituation to the reinforcer may be pooled across the two components of a concurrent schedule and across the two terminal links of a concurrent-chains schedule.

\section{REFERENCES}

Ahearn, W., Hineline, P. N., \& David, F. G. (1992). Relative preferences for various bivalued ratio schedules. Animal Learning \& Behavior, 20, 407-415.

Aoy Ama, K., \& MCSweEney, F. K. (2001). Habituation may contribute to within-session decreases in responding under high-rate schedules of reinforcement. Animal Learning \& Behavior, 29, 79-91.

AuTOR, S. M. (1969). The strength of conditioned reinforcers as a function of frequency and probability of reinforcement. In D. P. Hendry (Ed.), Conditioned reinforcement (pp. 127-162). Homewood, IL: Dorsey.

BAсоттI, A. V. (1977). Matching under concurrent fixed-ratio variableinterval schedules of food presentation. Journal of the Experimental Analysis of Behavior, 27, 171-182.

Bateson, M., \& KacelniK, A. (1995). Preferences for fixed and variable food sources: Variability in amount and delay. Journal of the Experimental Analysis of Behavior, 63, 313-329.

BATESON, M., \& KACELNIK, A. (1997). Starlings' preferences for predictable and unpredictable delays to food. Animal Behaviour, 53, 1129-1142.

Battalio, R. C., Kagel, J. H., \& MacDonald, D. N. (1985). Animals' choices over uncertain outcomes: Some initial experimental results. American Economic Review, 75, 597-613.

BAUM, W. M. (1974). On two types of deviation from the matching law: Bias and undermatching. Journal of the Experimental Analysis of Behavior, 22, 231-242.

BEDNEKOFF, P. A. (1996). Risk-sensitive foraging, fitness, and life histories: Where does reproduction fit into the big picture? American Zoologist, 36, 471-483.

Broster, B. S., \& RANKIN, C. H. (1994). Effects of changing interstimulus interval during habituation in Caenorhabditis elegans. Behavioral Neuroscience, 108, 1019-1029.

CARACO, T. (1980). On foraging time allocation in a stochastic environment. Ecology, 61, 119-128

Caraco, T., Blanckenhorn, W. U., Gregory, G. M., Newman, J. A.,
Recer, G. M., \& ZWicker, S. M. (1990). Risk-sensitivity: Ambient temperature affects foraging choice. Animal Behaviour, 39, 338-345.

Caraco, T., Martindale, S., \& Whittam, T. S. (1980). An empirical demonstration of risk-sensitive foraging preferences. Animal Behaviour, 28, 820-830.

CARTAR, R. V., \& Dill, L. M. (1990). Why are bumble bees risk-sensitive foragers? Behavioral Ecology \& Sociobiology, 26, 121-127.

Case, D. A., Nichols, P., \& Fantino, E. (1995). Pigeons' preference for variable-interval water reinforcement under widely varied water budgets. Journal of the Experimental Analysis of Behavior, 64, 299-311.

Cicerone, R. A. (1976). Preference for mixed versus constant delay of reinforcement. Journal of the Experimental Analysis of Behavior, 25, 257-261.

DAVIS, M. (1970). Effects of interstimulus interval length and variability on startle-response habituation in the rat. Journal of Comparative \& Physiological Psychology, 72, 177-192.

Davison, M. C. (1969). Preference for mixed-interval versus fixedinterval schedules. Journal of the Experimental Analysis of Behavior, 12, 247-252.

Davison, M. C. (1972). Preference for mixed-interval versus fixedinterval schedules: Number of component intervals. Journal of the Experimental Analysis of Behavior, 17, 169-176.

Duncan, B., \& Fantino, E. (1970). Choice for periodic schedules of reinforcement. Journal of the Experimental Analysis of Behavior, 14, 73-86.

Essock, S. M., \& REESE, E. P. (1974). Preference for and effects of variableas opposed to fixed-reinforcer duration. Journal of the Experimental Analysis of Behavior, 21, 89-97.

Fantino, E. (1967). Preference for mixed- versus fixed-ratio schedules. Journal of the Experimental Analysis of Behavior, 10, 35-43.

Fantino, E. (1969). Choice and rate of reinforcement. Journal of the Experimental Analysis of Behavior, 12, 723-730.

Fantino, E., \& Davison, M. (1983). Choice: Some quantitative relations. Journal of the Experimental Analysis of Behavior, 40, 1-13.

FleshleR, M., \& HoffMAN, H. S. (1962). A progression for generating variable-interval schedules. Journal of the Experimental Analysis of Behavior, 5, 529-530.

Frankel, P. W., \& vom SaAl, W. (1976). Preference between fixedinterval and variable-interval schedules of reinforcement: Separate roles of temporal scaling and predictability. Animal Learning \& Behavior, 4, 71-76.

GibBon, J. (1977). Scalar expectancy theory and Weber's Law in animal timing. Psychological Review, 84, 279-325.

GRACE, R. C. (1994). A contextual model of concurrent-chains choice. Journal of the Experimental Analysis of Behavior, 61, 113-129.

GRACE, R. C. (1996). Choice between fixed and variable delays to reinforcement in the adjusting-delay procedure and concurrent chains. Journal of Experimental Psychology: Animal Behavior Processes, 22, 362-383.

GRAHAM, F. K. (1973). Habituation and dishabituation of responses innervated by the autonomic nervous system. In H. V. S. Peeke \& M. J. Herz (Eds.), Habituation: Vol. 1. Behavioral studies (pp. 163-218). New York: Academic Press.

HA, J. C. (1991). Risk-sensitive foraging: The role of ambient temperature and foraging time. Animal Behaviour, 41, 528-529.

HA, J. C., LEHNER, P. N., \& FARLEY, S. D. (1990). Risk-prone foraging behaviour in captive grey jays, Perisoreus canadensis. Animal Behaviour, 39, 91-96.

Hamm, S. L., \& Shettleworth, S. J. (1987). Risk aversion in pigeons. Journal of Experimental Psychology: Animal Behavior Processes, 13, 376-383.

Hastjarjo, T., Silberberg, A., \& Hursh, S. R. (1990). Risky choice as a function of amount and variance in food supply. Journal of the Experimental Analysis of Behavior, 53, 155-161.

HERRNSTEIN, R. J. (1964). Aperiodicity as a factor in choice. Journal of the Experimental Analysis of Behavior, 7, 179-182.

Houston, A. I., \& McNAmara, J. M. (1982). A sequential approach to risk-taking. Animal Behaviour, 30, 1260-1261.

Hurly, T. A., \& OseEn, M. D. (1999). Context-dependent, risk-sensitive foraging preferences in wild rufous hummingbirds. Animal Behaviour, 58, 59-66. 
Hursh, S. R., \& FAntino, E. (1973). Relative delay of reinforcement and choice. Journal of the Experimental Analysis of Behavior, 19, 437-450.

Ito, M., TAKatsuru, S., \& SaEki, D. (2000). Choice between constant and variable alternatives by rats: Effects of different reinforcer amounts and energy budgets. Journal of the Experimental Analysis of Behavior, 73, 79-92.

Kacelnik, A., \& Bateson, M. (1996). Risky theories: The effects of variance on foraging decisions. American Zoologist, 36, 402-434.

Kagel, J. H., MacDonald, D. N., Battalio, R. C., White, S., \& GreEN, L. (1986). Risk aversion in rats (Rattus norvegicus) under varying levels of resource availability. Journal of Comparative Psychology, 100, 95-100.

KILLEEN, P. (1968). On the measurement of reinforcement frequency in the study of preference. Journal of the Experimental Analysis of Behavior, 11, 263-269.

LAming, P. R., \& McKinney, S. J. (1990). Habituation in goldfish (Carassius auratus) is impaired by increased interstimulus interval, interval variability, and telencephalic ablation. Behavioral Neuroscience, 104, 869-875.

Lawes, M. J., \& Perrin, M. R. (1995). Risk-sensitive foraging behaviour of the round-eared elephant shrew (Macroscelides proboscideus). Behavioral Ecology \& Sociobiology, 37, 31-37.

Leventhal, A. M., Morrell, R. F., Morgan, E. F., Jr., \& Perkins, C. C., JR. (1959). The relation between mean reward and mean reinforcement. Journal of Experimental Psychology, 57, 284-287.

Loвb, B., \& DAVISON, M. C. (1975). Performance in concurrent interval schedules: A systematic replication. Journal of the Experimental Analysis of Behavior, 24, 191-197.

Logan, F. A. (1965). Decision making by rats: Uncertain outcome choices. Journal of Comparative \& Physiological Psychology, 59, 246-251.

MacEwen, D. (1972). The effects of terminal-link fixed-interval and variable-interval schedules on responding under concurrent chained schedules. Journal of the Experimental Analysis of Behavior, 18, 253261.

Mazur, J. E. (1984). Tests of an equivalence rule for fixed and variable reinforcer delays. Journal of Experimental Psychology: Animal Behavior Processes, 10, 426-436.

Mazur, J. E. (1986). Fixed and variable ratios and delays: Further tests of an equivalence rule. Journal of Experimental Psychology: Animal Behavior Processes, 12, 116-124.

MAZUR, J. E. (1988). Choice between small certain and large uncertain reinforcers. Animal Learning \& Behavior, 16, 199-205.

Mazur, J. E. (2001). Hyperbolic value addition and general models of animal choice. Psychological Review, 108, 96-112.

MCNAmaRa, J. M. (1996). Risk-prone behavior under rules which have evolved in a changing environment. American Zoologist, 36, 484-495.

MCSwEenEy, F. K. (1992). Rate of reinforcement and session duration as determinants of within-session patterns of responding. Animal Learning \& Behavior, 20, 160-169.

McSweEney,F. K., Hinson, J. M., \& CAnnon, C. B. (1996). Sensitizationhabituation may occur during operant conditioning. Psychological Bulletin, 120, 256-271.

McSweeney, F. K., Murphy, E. S., \& Kowal, B. P. (2001). Withinsession changes in responding during concurrent variable interval variable ratio schedules. Behavioural Processes, 55, 163-169.

McSweeney, F. K., Roll, J. M., \& Cannon, C. B. (1994). The generality of within-session patterns of responding: Rate of reinforcement and session length. Animal Learning \& Behavior, 22, 252-266.

McSweeney, F. K., Roll, J. M., \& Weatherly, J. N. (1994). Withinsession changes in responding during several simple schedules. Journal of the Experimental Analysis of Behavior, 62, 109-132.

McSweeney,F. K., Swindell, S., \& Weatherly, J. N. (1996). Withinsession changes in responding during concurrent schedules with different reinforcers in the components. Journal of the Experimental Analysis of Behavior, 66, 369-390.

McSweeney,F. K., Swindell, S., \& Weatherly, J. N. (1999). Withinsession changes in responding during concurrent fixed interval variable interval schedules. Animal Learning \& Behavior, 27, 236-248.

McSineeney, F. K., Weatherly, J. N., \& Roll, J. M. (1995). Withinsession changes in responding during concurrent schedules that em- ploy two different operanda. Animal Learning \& Behavior, 23, 237 244.

McSweeney,F. K., Weatherly, J. N., \& Swindell, S. (1996). Withinsession changes in responding during concurrent variable-interval schedules. Journal of the Experimental Analysis of Behavior, 66, 7595.

Menlove, R. L., Inden, H. M., \& Madden, E. G. (1979). Preference for fixed over variable access to food. Animal Learning \& Behavior, 7, 499-503.

MorRIS, C. J. (1986). The effects of occasional short (FR 1) reinforcement ratios on choice behavior. Psychological Record, 36, 63-68.

NAVARICK, D. J., \& Fantino, E. (1972). Transitivity as a property of choice. Journal of the Experimental Analysis of Behavior, 18, 389401.

NaVARICK, D. J., \& Fantino, E. (1974). Stochastic transitivity and unidimensional behavior theories. Psychological Review, 81, 426-441.

NAVARICK, D. J., \& FAnTino, E. (1975). Stochastic transitivity and the unidimensional control of choice. Learning \& Motivation, 6, 179-201.

Perez, S. M., \& Waddington, K. D. (1996). Carpenter bee (Xylocopa micans) risk indifference and a review of nectivore risk-sensitivity studies. American Zoologist, 36, 435-446.

Pubols, B. H., JR. (1962). Constant versus variable delay of reinforcement. Journal of Comparative \& Physiological Psychology, 55, 52-56.

ReBoreda, J. C., \& KACELNIK, A. (1991). Risk sensitivity in starlings: Variability in food amount and food delay. Behavioral Ecology, 2, 301-308.

RIDER, D. P. (1979). Concurrent ratio schedules: Fixed vs. variable response requirements. Journal of the Experimental Analysis of Behavior, 31, 225-237.

RIDER, D. P. (1981). Concurrent fixed-interval variable-ratio schedules and the matching relation. Journal of the Experimental Analysis of Behavior, 36, 317-328.

Rider, D. P. (1983a). Choice for aperiodic versus periodic ratio schedules: A comparison of concurrent and concurrent-chains procedures. Journal of the Experimental Analysis of Behavior, 40, 225-237.

Rider, D. P. (1983b). Preference for mixed versus constant delays of reinforcement: Effect of probability of the short, mixed delay. Journal of the Experimental Analysis of Behavior, 39, 257-266.

Shafir, S., Wiegmann, D. D., Smith, B. H., \& Real, L. A. (1999). Risk-sensitive foraging: Choice behavior of honeybees in response to variability in volume of reward. Animal Behaviour, 53, 1055-1061.

Sherman, J. A., \& Thomas, J. R. (1968). Some factors controlling preference between fixed-ratio and variable-ratio schedules of reinforcement. Journal of the Experimental Analysis of Behavior, 11, 689-702.

Staddon, J. E. R., \& INNIS, N. K. (1966). Preference for fixed vs. variable amounts of reward. Psychonomic Science, 4, 193-194.

Stephens, D. W., \& Charnov, E. L. (1982). Optimal foraging: Some simple stochastic models. Behavioral Ecology \& Sociobiology, 10, 251-263.

Stubbs, D. A., \& Pliskoff, S. S. (1969). Concurrent responding with fixed relative rate of reinforcement. Journal of the Experimental Analysis of Behavior, 12, 887-895.

Thompson, R. F., \& SPencer, W. A. (1966). Habituation: A model phenomenon for the study of neuronal substrates of behavior. Psychological Review, 73, 16-43.

Trevett, A. J., Davison, M. C., \& Williams, R. J. (1972). Performance in concurrent interval schedules. Journal of the Experimental Analysis of Behavior, 17, 369-374.

Williams, B. A., \& Fantino, E. (1978). Effects on choice of reinforcement delay and conditioned reinforcement. Journal of the Experimental Analysis of Behavior, 29, 77-86.

Young, J. S. (1981). Discrete-trial choice in pigeons: Effects of reinforcer magnitude. Journal of the Experimental Analysis of Behavior, 35, 23-29.

Zabludoff, S. D., Wecker, J., \& CARACo, T. (1988). Foraging choice in laboratory rats: Constant vs. variable delay. Behavioural Processes, 16, $95-110$.

(Manuscript received November 21, 2002; revision accepted for publication March 3, 2003.) 